\title{
LAS MUJERES QUE EN EL SIGLO XVI GANAN DINEROS EN LAS BOTICAS
}

\author{
Working women in boutiques during the Sixteenth Century \\ Manuel Villegas Ruiz ${ }^{1}$ \\ maviru@terra.es \\ Fecha de recepción: $15-X I-2011$ \\ Fecha de aceptación: 5-I-2012
}

\begin{abstract}
RESUMEN: El presente estudio consiste en una breve aproximación histórica a la prostitución cordobesa en el siglo XVI. Con tal finalidad hemos adoptado dos puntos de vista complementarios: por un lado, las disposiciones y normativas vigentes en la época; por otro, su aplicación real según se desprende de las actas del Cabildo Municipal de Córdoba. El resultado pone de relieve situaciones de marginación que no son evidentes mediante el mero análisis formal de los textos legales.
\end{abstract}

Palabras clave: Manuel Villegas, Edad Moderna, Córdoba, botica.

ABSTRACT: The object of this paper is a synthesised historical approach to prostitution in Cordoba during the sixteenth century. For this purpose two views, integral one to another, are embraced: on the one hand, the examination of the legal texts in that period; on the other hand, its real enforcement according to Cordoba's City Council records. The findings of this study show the presence of social exclusion areas that are not self-evident through a mere formal analysis of legal texts.

Keywords: "Early Modern Period”, boutique, Cordoba, Manuel Villegas.

1 Dr. En Filosofía y Letras (Geografía e Historia). 


\section{INTRODUCCIÓN}

En este breve análisis, pues es parte de otro de mayor extensión aún en desarrollo, sólo pretendemos llevar a cabo una breve exposición histórica sobre la prostitución, dentro de unas coordenadas de espacio y tiempo. El lugar es la ciudad de Córdoba y el período, el siglo XVI. Entre otros aspectos, expondremos disposiciones encontradas en los legajos de esa época sobre las mancebas o prostitutas en dicho siglo y en la referida ciudad. Opinamos y no sin razón, como más adelante veremos, que esta situación es parecida o igual en el resto de las ciudades de la monarquía hispánica de aquel tiempo.

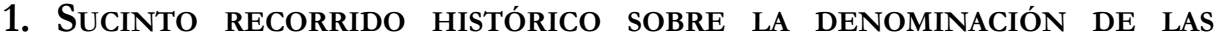 PROSTITUTAS}

El comercio carnal es tan antiguo como la civilización humana, por lo que no vamos a penetrar en la noche de los tiempos en busca de información sobre el tema, pero eso no quiere decir que no nos traslademos, al menos, hasta la Grecia y la Roma clásicas intentando encontrar un punto de apoyo y, desde él, llegar a la época en la que presentamos el trabajo, es decir, en el siglo antedicho.

Son muchos y distintos nombres con los que así en Grecia, como en Roma, servían para nombrar a las mujeres que se dedicaban a la venta de su cuerpo.

Los griegos clasificaban a las prostitutas en varias categorías, según el lugar que ocupasen dentro de su «oficio» y otros factores relacionados con

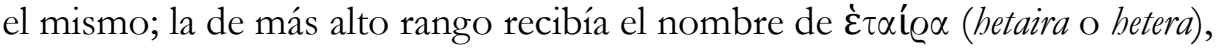
en su significación de compañera, amiga, querida, concubina, cortesana. En nuestra Edad Media nos encontramos con las «cántigas de amigo», que tenían la misma connotación de querido o querida.

A las de más baja condición las llamaban ro@va pornai). Su significado

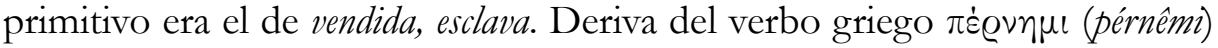

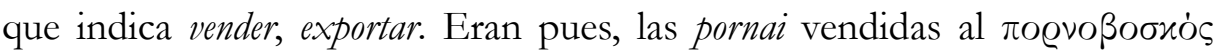

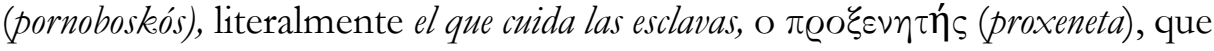
en su primitiva acepción equivalía a protector, patrón En la actualidad le damos un sentido totalmente insultante y ofensivo. 
De igual forma en Roma recibían distintos nombres, todos ellos relacionados, poco más o menos, con la forma de ejercer su oficio. Se las llamaban prostitutae, lupae (lobas), meretrices y de otras muchas formas como sucede también en otras culturas.

\subsection{La prostitución y la civilización cristiana}

Con la llegada del Cristianismo se formuló un explícito rechazo moral contra el sexo venal, pero se mantuvo su regulación, no para prohibirlo, sino para encauzarlo. Los antiguos fueron conscientes de esta aparente contradicción ya que consideraban que era reprobable, pero entendían que no se podía suprimir, y la justificaron acudiendo a la solución del mal menor.

Roger Benito Juliá en su trabajo Prostitución y Alcahuetería en la Barcelona del Siglo XV, nos dice:

«La prostitución es una actividad permitida en toda la Europa Medieval. Nos preguntamos: ¿cómo una sociedad tan cristianizada permite la prostitución? Se considera la prostitución como un mal menor y tiene una función específica: evitar males peores. Estos males son: la sodomía, el adulterio, las violaciones, la masturbación...San Agustín de Hipona escribe: «Apartad las prostitutas de los asuntos humanos y profanaréis todo con lujuria». Posteriormente San Tomás de Aquino apoyó esta idea en la Summa de Teología. El fraile franciscano Francesc Eiximenis en su obra Lo Cretià, recoge el testimonio de San Agustín y añade que las mujeres públicas no deben mezclarse con las honradas. Esta idea extendida por toda la Europa Medieval choca con nuestra mentalidad actual pero es vital para entender la prostitución en la Edad Media»².

Dentro de esta línea se mantienen teólogos tan ilustres como S. Vicente Ferrer, Alonso de Madrigal (El Tostado), Pedro de Costana y otros autores que aceptaban la existencia de los lupanares, siempre que estuviesen regulados por la autoridad ${ }^{3}$.

2 Benito Juliá Roger. Prostitución y Alcabuetería en la Barcelona del Siglo XV. Miscelánea Medieval Murciana 2008, XXXII; pp. 9-21; ISSN 0210-49031989-4597 Web www.scribd. com > Research > History. Fecha consulta 24-10-2012. ISSN 0210-4903.

3 Moreno Mengíbar Andrés. y Vázquez García, Francisco José, El Ocaso de las mancebias castellanas. Web: www.vallenajerilla.com/berceo/florilegio/florilegio/mancebia.htm. Fecha 
Podemos decir que los estamentos civiles y eclesiásticos han estado de acuerdo en cuanto a la aceptación de la prostitución siempre que estuviese dentro de unos límites que la reglamentasen y controlasen.

Más adelante veremos cómo en España, desde muy antiguo, los reyes y los concejos municipales intervinieron en su organización y funcionamiento, encauzado a controlar principalmente dos secuelas inherentes a la prostitución: la salud de los ciudadanos para evitar las enfermedades venéreas y los desórdenes públicos que en el entorno de dicho medio de vida se originaban.

\section{Lugar EN EL QUe SE ENCONTRABAN LAS PROSTItUTAS DENTRO DE LA SOCIEDAD}

Un somero repaso de las capas en las que la población estaba dividida en el momento histórico que estudiamos nos dice que estaba formada por tres grandes grupos en los que a su vez, se agrupaban otras subdivisiones.

Por orden de importancia eran:

-La Nobleza, compuesta por la alta y baja.

-El Clero, igualmente compartimentado en el alto y bajo

-Finalmente el pueblo llano que, podríamos decir, era el que aglomeraba mayores diferencias sociales. Éste constituía el grupo más numeroso, y, según la época, ha recibido denominaciones tales como la plebe, el común, el estado llano, las masas, etc. Su último escalón lo ocupaba la que podríamos llamar hez de la sociedad, en el que se daban cita todos los marginados rechazados de los restantes grupos sociales: los pícaros, los truhanes los buhoneros, la mayoría de los que no tenían arraigo en la sociedad, ni siquiera un lugar donde vivir o, si acaso, lo hacían precariamente, como así tan excelentemente han quedado descritos en nuestra literatura picaresca del siglo XVII.

Pues bien, en el mencionado grupo quedaban encuadradas las prostitutas de la más baja condición, a las que dedicamos una atención especial: Eran éstas las que practicaban su oficio en los mesones, en las tabernas o las que 
ganaban dineros en las boticas, como se las denomina en las actas capitulares; o mujeres públicas que ganan dineros, como también se las designa en documentos reales.

Añadamos además que eran personas libres, en tanto en cuanto que no estaban amancebadas con nadie, ni eran barraganas que conviviesen con alguien en particular, normalmente un clérigo, pero se encontraban bajo el dominio de sus proxenetas -ya comentaremos un escrito de los RR.CC. al respecto-y sometidas con frecuencia a los abusos y tropelías de los alguaciles, oficiales de la Justicia y de los Regimientos municipales; tanto es así que en más de una ocasión los reyes tuvieron que intervenir para evitar tales abusos, como, llegado su momento, expondremos.

\subsection{Su reclusión en las mancebías}

Se llamaba «mancebía» no sólo a la casa de prostitución, sino también al conjunto de ellas. Consideramos que con esa palabra se designaba más el concepto o la idea del meretricio que los locales en los que se practicaba expresamente

Posiblemente, unas de las situaciones que más daño podría causar a estas mujeres era la de su aislamiento de la sociedad, pues su libertad de movimientos se restringía solamente a las casas-botica y a sus aledaños.

En ellas vivían como enclaustradas en un convento, tal como se comprueba en una orden expedida a principios del XVI en Toledo que mandaba refundir en un solo volumen todas las ordenanzas de Sevilla. Este trabajo fue imprimido en 1527, en un solo cuerpo en folio, y constaba de 37 capítulos, entre los que había uno dedicado a las mujeres deshonestas. He aquí la disposición referente al confinamiento de las mismas:

«E por que la castidad, en mi tiempo no podía facer tal cosa: Ordeno e mando no fagan los tales ayuntamientos de mugeres; mas que no quisieron ser buenas e castas, é quisieren vender sus cuerpos, que se pongan y estén en la mancebía pública, á do están las otras mundarias públicas; y las que contra esto ficieren, que demás de las otras penas ordenadas, que les den veynte azotes publicamente; e á la que estuviere por mayoral della, que por la primera vegada que en este yerro fuere fallada, que le den cincuenta azotes 
publicamente, e por la segunda vegada que en este yerro fuere fallada, que le den cien azotes publicamente, e por la tercera que le corten las narices e le echen de la Cibdad para siempre... $»^{4}$.

«Otrosí; por quanto fue denunciado é dicho, que en esta çibdad de Sevilla avía casas que se llamaban "monesterios" de malas mugeres que usaban mal de sus cuerpos en pecado de la luxuria, y que tenían una mayoral a manera de abadesa, y que aquella como encubiertamente, y como a manera de orden de luxuria, alquilava á las mugeres malas que allí estaban por usar de esta maldad; é aún que algunas veces acaesçia por quanto estas tales malas mugeres, que asi estavan ayuntadas à manera de colegio faxían sus luxurias é maldades mas encubiertamente que las mundarias públicas: que algunas mugeres casadas é viudas é honestas é virgenes que entraban en las tales casas, y que acaescía que facían ende algunos errores, lo cual es gran deservicio a Dios, é cosa de mal ejemplo». 5 .

En Córdoba estas mujeres ejercían su profesión, más adelante lo comprobaremos, en una zona muy bien delimitada en la que se daba la mayor concentración de mesones, posadas, tiendas, talleres de artesanos, etc. Era durante el día, momento en el que se realizaban la mayoría, si no todas las transacciones comerciales, cuando más se las solicitaba. Por ello era lógico que, al llegar la noche, deseasen ir a su casa a dormir, pero era tal era su aislamiento, la presión que sobre ellas se ejercía y las vejaciones a las que eran sometidas que no podían hacerlo si no pagaban previamente a los alguaciles mayores un real, como más adelante manifestaremos. Posteriormente, cuando expongamos las exigencias pecuniarias a las que eran sometidas comprobaremos que tanto la reina $\mathrm{D}^{\mathrm{a}}$ Juana, como más tarde su hijo Carlos tuvieron que dirigirse al Cabildo cordobés para prohibir que estas mujeres pagaran un dinero al que no estaban obligadas.

4 La prostitución en la Sevilla del Siglo XVI. Alma Mater Hispalense, Siglo XVI Web: http://personal us.es/alporu/histsevilla/prostitución.htm. Fecha consulta 7-10-2011. Sin ISSN, ni ISBN.

5 Ibidem 


\section{Primitiva ubicación de la mancebía en la Córdoba del siglo XVI}

En aquella época existían dos barrios en Córdoba con el nombre de S. Nicolás: uno era el de S. Nicolás de la Villa, ubicado en la zona noble y amurallada, llamada «Medina», cuya parroquia todavía pervive; el otro, denominado S. Nicolás de la Axerquía o simplemente «Axerquía», constituía uno de los arrabales de la ciudad y se encontraba, al inicio, como el resto de los mismos, fuera de la primitiva muralla de la misma. Con el tiempo estos barrios se fueron extendiendo y ganando en población hasta alcanzar tanto auge que llegaron a superar en extensión a la propia medina.

Posiblemente esta collación ${ }^{6}$ de la Axerquía fuese la de mayor tráfago comercial de la ciudad. Para que el lector conozca más fácilmente dónde se hallaba ubicada, insertamos unos planos tomados de la comunicación realizada en las Actas del III Coloquio de Historia Medieval Andaluza que presentaron Jesús Padilla González y José Manuel Escobar Camacho?.

No es nuestro propósito hacer una pormenorizada descripción de la mencionada collación, pero, no obstante, en la parte inferior de la primera representación, podemos observar con toda claridad que, en la calle de El Potro, cercana al Río Guadalquivir, hay una calleja o barrera, denominada calle de la Mancebía en la que se encontraban agrupadas el mayor número de casas-boticas en las que se ejercía tal oficio. La calleja o barrera se cerraba en fiestas religiosas señaladas, como por ejemplo, en Semana Santa con el fin de impedir el comercio de la prostitución. Señalemos que, quien en estas celebraciones quebrantara tal prohibición estaba penado con sanciones pecuniarias y, a veces, incluso hasta con castigos corporales.

En el segundo plano el lector puede apreciar más pormenorizadamente la barrera, ya mencionada, en la que se ubicaba la primitiva mancebía; la gran cantidad de mesones, nada menos que doce, enclavados en un espacio ciertamente reducido, así como ocho boticas que, sumadas a los doce mesones referidos, alcanzan un total de veinte locales en los que se practicaba la prostitución. De igual manera se pueden comprobar los distintos talleres

\footnotetext{
6 N.B. Se denominaba collación a lo que hoy conocemos como barrio o barriada 7 Jesús Padilla González, y José Manuel Escobar Camacho. La Mancebia de Córdoba en la Baja Edad Media. Actas del III Congreso de Historia Medieval Andaluza. La Sociedad Medieval Andaluza: Grupos no privilegiados Instituto de Cultura, 1984. Diputación Provincial de Jaén, 1984, págs. 279-281. ISBN.: 84-505-0834-7.
} 
de los diferentes artesanos que, con su actividad laboral y comercial, daban vida a toda esta área propiciándola para el comercio carnal.

También se puede comprobar la existencia de una calle y un adarve denominados De la Mancebía, cosa que nos puede dar una idea del auge que ha experimentado toda esta collación y del aumento de tráfico comercial y de la circulación de personas que, a no dudar, motivaron que la reducida franja en la que existían las mancebías iniciales se extendiese de manera tan considerable.

Otro motivo más que ocasionaba el bullicio de esta barriada era que cerca de la misma, pero dentro de la antigua muralla, se hallaba el pósito de la ciudad, distrito igualmente de mucho tráfico comercial y de negocios. Por ello, la inicial localización del meretricio no quedó sólo circunscrita a la calleja mencionada sino que, como hemos dicho, con el tiempo se extendió por sus alrededores como consecuencia del gran movimiento de personas que deambulaban por ellos y que alimentaban este negocio

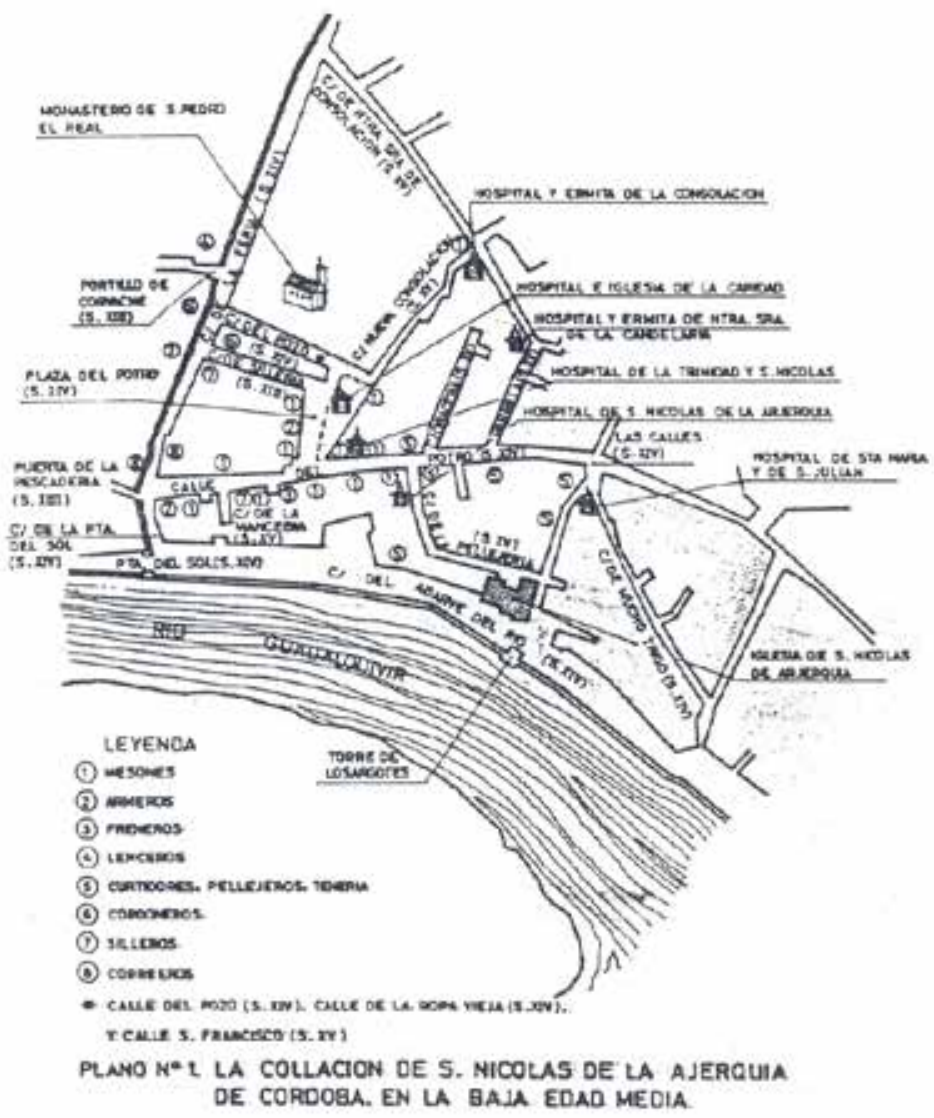



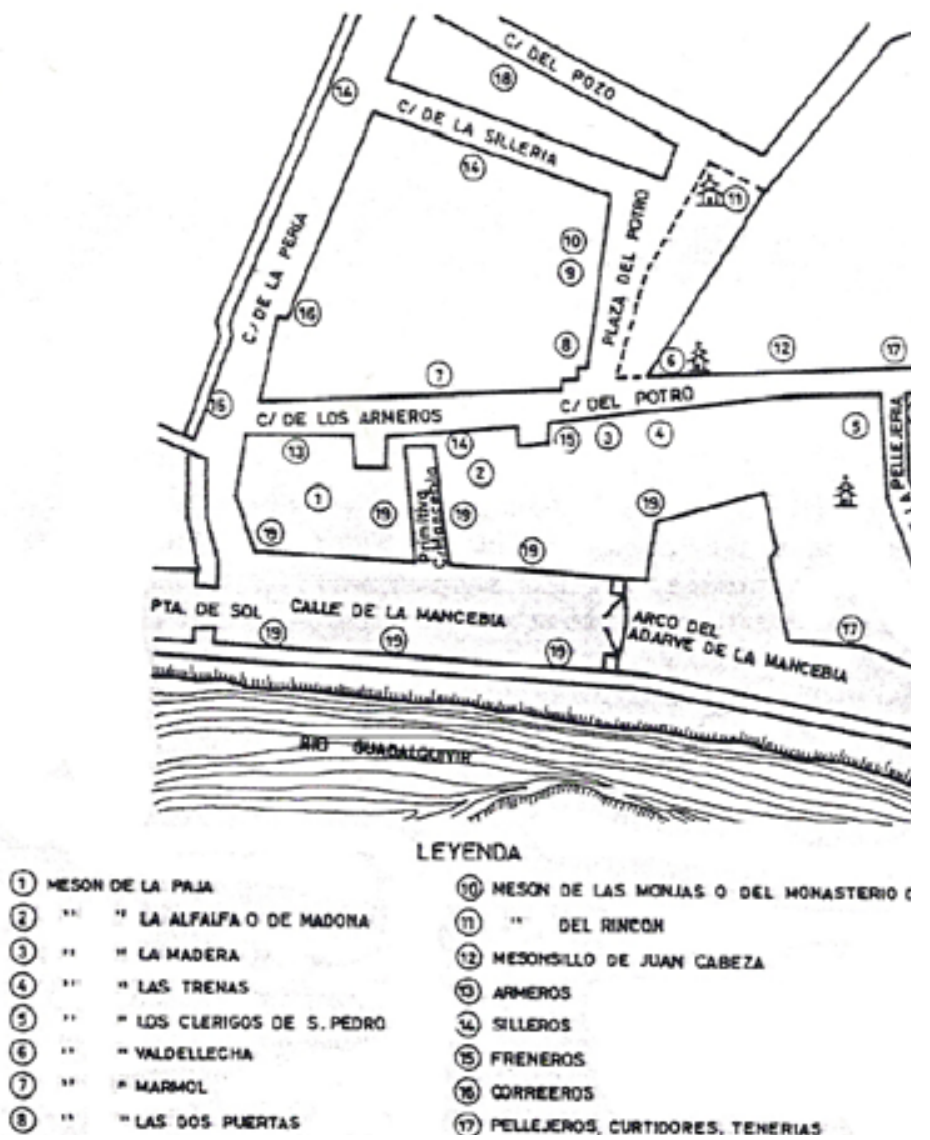

(19) MESON OE LAS MONHAS O OCL MOMASTERIO \&

(1) * DEL RENCOH

(12) mesoresuo oe ruar cabeza

(D) APMEROS

(3) surros

(B) FREMEROS

(3) MRAEERos

(Di) PEUESEROS, CURTIDORES, tenerus

\section{1 ¿Cómo estaba organizada la Mancebía?}

La regulación, inspección y vigilancia de las mancebías correspondía al Cabildo municipal y a la Corona, quienes con sus disposiciones determinaban e implantaban las normas a las que debería ajustarse el buen funcionamiento de las mismas.

Tenemos constancia de que, como mínimo desde el año 1435, existen en Córdoba unas ordenanzas en las que ya se habla de estas mujeres.

A continuación exponemos brevemente un extracto del escrito que Felipe II dirigió a Córdoba el 19 de marzo de 1571 que es reproducción, más o menos literal, con algunas supresiones y añadidos de las ordenanzas sevillanas de $1553^{8}$.

8 A.M.H.CO Sección: Fuero, privilegios, Acontecimientos reales y Docum. Miscelánea. 
De esta síntesis destacamos los siguientes aspectos:

-Hace responsables directos de las casas de camas a los llamados Padres de la mancebía fijando además unas normas estrictas por las cuales aquellas se han de regir y cómo debe ser el comportamiento de los mismos, imponiendo multas pecuniarias, azotes y hasta destierros de la localidad en caso de reincidencia en el incumplimiento de lo mandado.

También prohíbe que dichos padres puedan por ellos ni otra persona en su nombre directa ni indirectamente alquilar ropa alguna, ni camisa, ni toca, ni gorguera, ni saya ni sayuelo ${ }^{9}$, ni otra cosa alguna a ninguna mujer de la dicha mancebía, so pena de que por la primera vez que ello hiciere y fuere probado pague de multa mil maravedíes y pierda todas las ropas que así alquilaren.

-Pormenoriza taxativamente cómo han de comportarse en el trato con las meretrices y los castigos que sufrirían, en el caso de que abusaran de ellas al proporcionarles la comida o la bebida diarias.

-Especifica claramente que todos los ayuntamientos han de tener un cirujano y un médico, quienes cuidarían de la salud de las prostitutas y tendrán que examinarlas una vez al mes.

-Antes de ser acogidas en las casas deberán ser inspeccionadas por el médico, y, si no se llevase a cabo tal reconocimiento, hace responsable de ello a los mencionados padres de la mancebía.

-Dicta normas incluso de lo que les ha de cobrar por la habitación y los utensilios necesarios.

No son éstas todas las medidas que contiene el mandato de Felipe II, pero

Subsección: Mancebía. Serie: Disposiciones y expedientes. Signatura: C 0016 008. Ident. Regist.: 10.590.

9 N.B. Por ser atuendos totalmente en desuso hoy día, pensamos que no está de más, explicar cada uno, según las definiciones del DRAE: La toca era una prenda, normalmente usada por las mujeres para cubrirse la cabeza. Algunas monjas las siguen hoy utilizando. La gorguera consistía en un adorno del cuello, hecho de lienzo plegado y almidonado que usaban tanto los hombres cuanto las mujeres. La saya era una especie de falda. El sayuelo una prenda suelta y corta de mujer, generalmente con mangas que cubría el busto y llegaba hasta la cadera. Podía llevarse suelto o recogido por delante con cordones o algún otro elemento a modo de ceñidor. Fue una prenda muy extendida en los siglos XVI y XVII. 
sí son una muestra de la rigidez del mismo; por otra parte, las ordenanzas municipales dictaminaban que el Regimiento municipal cordobés tenía que nombrar un caballero veinticuatro y un jurado ${ }^{10}$ para que vigilaran el cumplimiento de estas reglas emanadas de dicho cabildo, así como que las casas-botica debían permanecer totalmente clausuradas durante la Semana Santa. Esta disposición, ya recogida con anterioridad en otros ordenamientos gubernamentales, se extiende como norma de obligado cumplimiento para el resto de la Corona española. Caso de que el padre de la mancebía o alguna de las mujeres no la obedeciere, incurriría en pena pecuniaria, además de recibir cien azotes.

\section{OTRAS PRESCRIPCIONES REALES Y MUNICIPALES SOBRE LAS MANCEBÍAS}

Antes de entrar de lleno en las disposiciones legales, debemos mencionar los requisitos que se les exigían para ejercer la prostitución.

Según nos manifiesta J. Cobos, hasta finales del siglo XVI, cualquier mujer que quisiese dedicarse a ello debería demostrar ante un juez, que tenía más de doce años (nos recuerda esto que a los lupanares también se les conocía como «casas de niñas», o «ir de niñas» al hecho de visitarlos), que ya no era virgen o que no tenía padres, es decir, era huérfana, y abandonada por el resto de sus familiares ${ }^{11}$.

\section{1 ¿Por qué las autoridades se han preocupado siempre de las prostitutas?}

Desde muy antiguo, los monarcas y los cabildos municipales se han

10 N.B. Los caballeros veinticuatro, así llamados en Andalucía, son los regidores del resto de las ciudades castellanas. Eran los que administraban y gobernaban la ciudad; mutatis mutandis podríamos equipararlos a los concejales de hoy día. En las reuniones municipales tenían voz y voto. Los jurados, eran los representantes de los habitantes de las distintas collaciones que componían la ciudad. Asistían a los cabildos municipales con voz, pero sin voto.

11 Cobos Ruiz de Adana, J. Delincuencia y sexualidad en la Córdoba barroca. Cursos de Verano El Barroco en Andalucía. Tomo II. Universidad de Córdoba y Excm ${ }^{\mathrm{a}}$ Diputación Provincial de Córdoba. Córdoba, 1984, pp. 65-76. ISBN 84-600-3626-X .Depósito Legal CO 774 1984. 
desvelado y ocupado en regular este modus vivendi. Y consideramos que las razones principales que justificaban tal preocupación eran éstas:

- Velar por la salud pública, evitando la transmisión de las enfermedades venéreas

-Impedir los comportamientos antisociales derivados de tal actuación.

-Evitar la posibilidad de que estas mujeres, por su atuendo, pudieran parecer o asemejarse a las que no practicaban esta profesión, es decir, las llamadas mujeres decentes.

Y en último lugar, pero no menos importante, la recaudación de impuestos a los dueños de los mencionados locales, así como a las mismas prostitutas, aunque había ciudades que no imponían gravámenes por ello, como Sevilla ${ }^{12}$.

Seguidamente y de la forma más breve posible, analizaremos, en epígrafes separados, cada uno de los motivos anteriormente expuestos.

\subsubsection{La salud de las prostitutas}

Respecto a esta primera consideración, ya hemos visto cómo Felipe II se preocupa de ella en las ordenanzas antes comentadas.

En lo que concernía al Ayuntamiento cordobés, debía éste contar con médico y cirujano, quienes habrían de realizar un reconocimiento médico a dichas mujeres cada ocho días. Por otra parte ellas, antes de ejercer su oficio, tenían que someterse a un examen sanitario cuyo resultado había de ser puesto en conocimiento de los diputados municipales quienes determinaban, según éstas se encontrasen de salud, qué prostitutas debían ser hospitalizadas Por tanto las que padeciesen algún mal no podían permanecer en el prostíbulo, siendo el responsable del mismo quien debía comunicar tal hecho a los diputados municipales. La norma, pues no podía ser más clara ni más precisa, aunque más adelante veremos cómo, una vez dictada ésta, se buscaban subterfugios para no cumplirla.

12 Vide nota 5. 
Veamos algunos casos que atestiguan lo que antes hemos afirmado:

En la sesión de cabildo, celebrada el 6 de junio de 1533, se comisiona al jurado Juan de Heredia para que busque un cirujano que cate a las mijeres que ganan dineros y obtenga de cada una de ellas seis maravedies al mes ${ }^{13}$.

El día 20 del mismo mes entra en la sala de sesiones del Cabildo el cirujano maese Luis y jura el oficio que ha de desempeñar, por el cual se le pagarían ocho maravedíes al mes por cada mujer que reconociese. Además se le autoriza para que lleve alguaciles que eviten que se le impida realizar tal reconocimiento bajo pena de 6.000 maravedíes a quienes se opusiesen a ello ${ }^{14}$.

Dicho cirujano debería practicar el mismo reconocimiento a aquellas que, por primera vez, se trasladaran a Córdoba para ejercer este oficio.

Posiblemente esta revisión médica no se efectuaba con la rigidez o periodicidad prescritas, pues el caballero veinticuatro D. Diego de los Ríos pide, en la sesión municipal celebrada el 9-8-1535, que se nombre a una persona que reconozca a las mujeres del burdel por el daño que se sigue a la salud ${ }^{15}$. Dos días después se da un mandamiento para que el mencionado maestre Luis entienda en lo de las mujeres de la mancebía, como conviene a la salud de la gente y que lo use por todo el año ${ }^{16}$.

\subsubsection{La eliminación y/o evitación de los comportamientos antisociales consiguientes a tal actuación}

El oficio de alcahuete o proxeneta viene desde muy antiguo. En el vocabulario griego existe la palabra $\pi \varrho o \xi \varepsilon v \eta \imath \dot{s}$ (proxenetés) equivalente a la latina proxeneta, del mismo significado que la también latina leno, usada para denominar al mercader de mujeres esclavas. El proxenetismo, la alcahuetería, la putería y el juego acarrean como consecuencia comportamientos inevitables contrarios al buen orden y recto gobierno de la sociedad.

13 A.H.M.CO. Actas capitulares. Sesión del 6-6-1533. Signatura L-36

14 Ibidem. Sesión del 20-6-1533. Signatura L-36.

15 Ibidem. Sesión del 9-8-1535. Signatura, L-37.

16 Ibidem. Sesión del 11-8-1535. Signatura L-37. 
Alfonso X en la Partida 7, título 22, Ley 1, cuando habla de los alcahuetes, dice:

«Y son cinco maneras de alcahuetes, la primera es de los bellacos malos que guardan putas públicamente en las puterías, tomando su parte de lo que ellas ganan...y aun decimos que, sin todo ello, levántase por los hechos de ellos desacuerdos y muchas peleas y muertes de hombres».

También manifiesta en la misma:

«...y después que les fuere probada la alcahuetería, debenlos echar fuera de la villa a ellos y a las putas $Y$ si alguna alquilase sus casas a sabiendas a mujeres malas para hacer en ellas putería, debe perder la casa y ser de la cámara del rey y además debe pagar diez libras de oro» ${ }^{17}$.

Continúa luego enumerando el resto de tipos de alcahuetes, pero consideramos que con la mención hecha es más que suficiente.

También las ordenanzas del Cabildo cordobés de 1435, ya mencionadas, prohíben, con las siguientes palabras, que las rameras no sean utilizadas por los rufianes y que los alguaciles y sus peones no les confisquen cosa alguna:

«Y putas públicas y rameras

Que ninguna puta pública no sea amiga de ombre alguno syn su grado e el alguacil e sus peones no tomen cosa alguna a ninguna mujer sy non fuere puta pública e de las otras a que llaman encubiertas que les no tomen cosa alguna ny las metan en mala fama porque podría de ello hacer escándalo e otros dannos» ${ }^{18}$.

Las inquietudes de los monarcas y de los cabildos municipales para evitar comportamientos inadecuados son constantes. Así podemos ver cómo los Reyes Católicos emiten una carta, fechada en Córdoba el día diecinueve de diciembre del año 1491, que la envían a los concejos de Sevilla, Córdoba, Écija y Carmona, parte de cuyo texto nos parece oportuno exponer:

«...por las leyes de nuestros reynos está defendido so grandes penas que

17 Microsoft Word - Alfonso_X_El_Sabio__Las_Siete_Partidas.doc pensamientopenal.com.ar/46partides.pdf · archivo de PDF. Fecha consulta 25/5/2011 18 A.M.H.CO. L-1905, folios. 15 vuelto, 16 recto. 
ninguna mujer del partido tenga rufián, ni persona alguna tenga mujer al partido muchos ombres tienen mujeres al partido en esas dichas çibdades e muchas mujeres tiene rufianes e que por escusar de la pena en que por esto an están las dichas mujeres en esas dichas çibdades e villas e los rufianes en Fuentes e en Guadalcázar e en el Carpio e en otros lugares de señorío [...] tableros e juegan con los [...] e aun tienen dados e naypes falsos con que les ganan e roban con ruydos o hazen otros males e dannos e que se van de noche donde están a ver e holgar con las dichas mujeres e porque esto es deserviçio de Dios e danno de la República...» ${ }^{19}$.

El escrito es más extenso y en él se pormenoriza cómo deberán actuar las justicias de los mencionados concejos, así como las multas y penas que impondrán a quienes no cumplan con el referido mandato.

\subsubsection{Impedir que estas mujeres, por su vestimenta, no sean confundidas con las llamadas decentes}

Hemos encontrado y transcrito varios documentos, ya reales, ya municipales, en los que se dan normas referentes al atuendo que están obligadas a usar dichas personas pero que, en algunos casos, los mandatos se contradicen.

Las citadas ordenanzas de Felipe II manifiestan taxativamente que:

«No deberán cubrirse con vestidos diferentes y señoriales donde sean conocidas, y fuera de la mancebía no podrán llevar mantas, ni sombreros, ni guantes ni pantuflos ${ }^{20}$. Solamente deberán ir cubiertas por mantillas cortas de color amarillo que encubrirán las ropas que lleven debajo. Caso de su atuendo fuese otro perderán la ropa que lleven y además abonarán una multa de trescientos maravedíes».

José Cobos expone que en las ordenanzas de Sevilla se mandaba que las

19 A.M.H.CO. Sección: fuero, Privilegios, Acontecimientos reales, y docm. Miscelánea. Subsección: Mancebía. Serie: disposiciones, normativas y expedientes. Cod. Archivo AH.01.17.01. Signatura: C-0016-002.

20 N.B. El pantuflo, según el diccionario de la R.A.E, procede del francés pantoufle y es un calzado, especie de chinela o zapato sin orejas ni talón, que para mayor comodidad se usa en casa. Posiblemente en aquella época también para la calle. 
mujeres que viviesen en la mancebía debieran ir sin mantas, sin sombreros, sin guantes...etc y que sólo pudieran llevar «mantillas amarillas cortas, sobre las sayas que truxerenı ${ }^{21}$.

Jesús Padilla y José Manuel Escobar, en el trabajo mencionado, manifiestan que en el Ordenamiento de las Cortes de Valladolid de 1537, se prohíbe a las mujeres del partido llevar, dentro y fuera de sus casas, joyas y vestidos de lujo 22 .

El reglamento de Felipe II que acabamos de examinar anula el emitido por su padre, el rey Carlos el 15-12-1526, en el que promulga una real provisión dirigida al Corregidor, Juez de Residencia, o al alcalde o lugarteniente de dicho oficio, en la que manifiesta que ha recibido quejas de Marcos Muñoz, vecino de Córdoba, quien le expone que a ... algunas de las mujeres enamoradas de la mancebía...acostumbran a tener por ornamentos de sus personas faldas, mantos guarnecidos, sombreros, sayuelos de paño y de damasco, así como zarcillos de plata y sortijas y otras ropas con las que se atavían; y los alguaciles de Córdoba se los quitan, por lo que solicita a su Majestad que no consienta en ello. El Consejo real acordó que los alguaciles de la ciudad no desposeyesen a las referidas mujeres de cosa alguna de las que llevasen para su indumentaria y que les restituyeran las que le hubiesen tomado, y que, desde entonces en adelante, no lo volviesen a hacer, bajo pena de la merced real y de 10.000 maravedíes para la Cámara real23

Anteriormente el Cabildo municipal de Córdoba el 18-5-1515, había emitido una disposición por la cual las referidas mujeres no podían lucir por las calles fuera de la mancebía oro, plata, ni mantillo cobijado, ni seda fina, ni falsa, desde el día de Pascua del Espíritu Santo en adelante, salvo que las hubiese pedido y que no fuesen suyas ${ }^{24}$.

Son muchas, pues las disposiciones reales y ordenanzas municipales de los distintos cabildos urbanos de España que hablan a este respecto en diferentas épocas y, según hemos apreciado, tales instrucciones son a veces contradictorias, lo que indica que en algunas ocasiones ni lo mismos

21 Cobas Ruiz de Adana, José. Op. cit, pág. 71

22 Padilla Gonzáles, Jesús. y Escobar Camacho, José. Manuel. Op. cit. Pág. 287, nota 45.

23 A.H.M.CO. Sección Fuero, Privilegios, Acontecimientos reales y doc. Miscelánea. Subsección Mancebía .Serie. Disposiciones normativas y expedientes. Cod. Archivo AH 01.17.01. Signatura: C 0016 006. Ident. Regist.: 10.588.

24 Ibidem. Signatura 0016003 Ident. Regist: 10.585. 
poderes gubernamentales se ponían de acuerdo respecto a la indumentaria que habrían de llevar las mujeres públicas para que no se confundiesen con las honestas.

Además, desde que las ordenanzas de Felipe II son normas de obligado cumplimiento para toda la Monarquía Hispánica ${ }^{25}$, ya no queda duda de que estas mujeres han de vestir de forma que se reconozca que son mundarias y no pertenecen a las llamadas decentes.

Como última razón que motiva a las autoridades a controlar a la prostitución, analicemos el siguiente apartado:

\subsubsection{La exigencia de impuestos a las prostitutas}

Nos consta que había ciudades, una de ellas Sevilla, en las que estas personas estaban exentas de pagar impuestos por el ejercicio de su profesión ${ }^{26}$.

Sin embargo el Cabildo municipal cordobés tiene regulada y fijada la cantidad que ellas habían de pagar como tributo. Aunque, por lo que en las ordenanzas de 1435, ya mencionadas, se expone no queda suficientemente claro si el beneficiario es el Ayuntamiento o son los peones del alguacil, ya que en ellas se expresa taxativamente:

«Derechos de las putas.

Toda puta pública que viniere a la çibdad dé un maravedí de entrada a los peones del alguacil e non dé otro derecho salvo lo que es costumbre de dar el sábado que es un maravedí cada una» ${ }^{27}$.

Específicamente se manifiesta que cada sábado debían de abonar un maravedí. ¿Quién era el beneficiario? Nuestra opinión personal es que se trata de una gabela que entra directamente en las arcas municipales, pues más adelante comprobaremos los ingresos que recibía el Cabildo por tal actividad.

25 N.B. Las ordenanzas las dirige Felipe II «... a todos los corregidores, alcaldes y justicias de las ciudades y a todas las otras villas e lugares de los nuestros reinos...». Vid. nota 9

26 Vide nota 12.

27 A.M.H.CO. L-1905, pp. 15 vuelto, 16 recto y 16 vuelto 
También perjudicaban en este sentido a sus pupilas los padres de las mancebías, los cuales les exigían diariamente medio real de plata, es decir, diecisiete maravedíes.

Tal abuso viene de muy antiguo, pues también Padilla González y Escobar Camacho, en el mencionado trabajo, nos manifiestan que en el año 1491, en virtud de un acuerdo logrado en el pleito que las prostitutas habían puesto al deán y al cabildo catedralicio y restantes propietarios de los burdeles, se determinó que no se les cobrase el aludido medio real de plata y éstas abonasen solamente doce maravedíes al día por la botica y la cama ${ }^{28}$.

El grado de coerción por parte de las autoridades de la ciudad de Córdoba es tal que los reyes, ante los requerimientos de que han sido objeto por ello, se ven obligados a intervenir y exigir al Concejo cordobés que no consienta tales exigencias. Así, la reina $\mathrm{D}^{\mathrm{a}}$ Juana, en una real provisión emitida en Plasencia el 7-12-1515 y dirigida al Corregidor para los alguaciles de Córdoba, manifiesta que ha recibido quejas de que éstos cobran un real de plata a cada mujer que de noche sale fuera de la mancebía para dormir en su casa, y asimismo manda a los corregidores y jueces del Regimiento municipal que no consientan ni den lugar a que los alguaciles mayores cobren a las referidas mujeres dinero alguno cuando quieran salir a dormir fuera de la mancebía ${ }^{29}$.

De la misma manera su hijo Carlos en un escrito del 25 de agosto de 1525, dirigido al Corregidor de Córdoba, le expone que ha recibido quejas de Juan de Molina, guarnicionero de esta ciudad que posee trece casas y un mesón en la mancebía de la misma, porque «...los alguaciles e otras justicias de esa dicha çibdad llevan muchos cohechos a las dichas mujeres e les ponen muchas imposiciones especialmente que diz que cada vez que quieren salir de noche a dormir fuera llevan a cada una de ellas un real,... e porque diz que paga de tributo en cada año por razón de las trece casas e un mesón veinte e un mil maravedíes...»

Por lo cual dispone, según había dictaminado el Consejo real, que el Corregidor, sin dar lugar a dilaciones de malicia, busque sólo la verdad y

28 N.B. El real de plata, en aquella época, valía 34 maravedíes. Gran logro consiguieron las prostitutas al obtener que la cantidad que abonaban se redujese en 5 maravedíes.

29 A.M.H.CO., Sección: Fuero, privilegios, Acontecimientos reales y Docum. Miscelánea. Subsección: Mancebía. Serie: Disposiciones y expedientes. Signatura: C 0016 004. Ident. Regist.: 10.586. 
administre justicia a las partes para que éstas no reciban agravio, ni que los alguaciles den motivo ni razón para que se produzcan nuevas quejas ante él, bajo pena de su merced y de 10.000 maravedíes para la Cámara real ${ }^{30}$.

Por lo tanto, podemos afirmar con total rotundidad que el Cabildo cordobés lograba pingües beneficios de estas mancebías por distintos conceptos, como eran, el de apertura de dichos establecimientos a sus dueños o arrendatarios -100 maravedíes en el año 149931.-, el tributo anual del mantenimiento de esas casas y mesones-ya hemos referido el caso de Juan de Molina-, y las multas impuestas por los alguaciles a las prostitutas y padres de las mancebías.

Según lo hasta ahora expuesto, podemos hacernos una idea de la situación tan despreciable y humillante en el que se encontraban inmersas estas mujeres en la época que comentamos.

Para concluir, creemos que debemos preguntarnos a quiénes favorecía más esta situación; consideramos que la respuesta es bien sencilla, breve y clara

\section{5. ¿QUIÉNES SON LOS MÁS FAVORECIDOS POR ESTA SITUACIÓN?}

Los más beneficiados eran aquellos componentes de la sociedad que por sus principios, por la desaprobación y rechazo público en el que podían verse inmersos, por su honorabilidad oficial, aunque no privada, y por el status social que ocupaban deberían haber rechazado, sin dudar lo más mínimo, el comercio del trato carnal.

Los integrantes de los cabildos catedralicios poseían, a título particular e incluso la corporación como tal, tabernas, mesones y boticas en las que se ejercía manifiestamente el meretricio. Los investigadores Padilla González y Escobar Camacho, en su trabajo ya citado, exponen que el Cabildo catedralicio cordobés fue, durante toda la Baja Edad Media, dueño de los mesones de la Paja, y de la Alfalfa o Madona. Igualmente, reseñan que también personas relacionadas con la Corte real los Consejos municipales, así como ciertos

30 Ibidem. Signatura: C 0016 005. Ident. Regist.: 10.586.

31 Jesús Padilla González y José Manuel Escobar Camacho. Op. cit. pág. 285. 
individuos pudientes que, por su situación económica, incluidos artesanos, se lo podían permitir poseían en propiedad o arrendaban prostíbulos ${ }^{32}$.

Lamentamos que los documentos hallados y consultados no nos hayan podido proporcionar la cantidad que los dueños de estos locales tenían que pagar por la explotación de los mismos, pero deducimos, que debería ser un montante bastante considerable para todos los que, de forma indirecta $\mathrm{O}$ indirecta, tenían en ellos una de las formas de su modus vivendi.

Ya hemos hablado de qué manera, tanto los alguaciles, como sus peones extorsionaban a estas mujeres, pues queda claramente reflejado en los documentos reales mencionados, cobrándoles indebidamente un real de plata cuando por la noche querían abandonar la mancebía. También hemos comentado los documentos reales en los que mandan al alguacil mayor de Córdoba, así como a su Concejo que no permitan que los alguaciles perciban esa injusta cantidad.

Suponemos que este Juan de Molina, del que ya hemos hablado, debió ser un personaje acaudalado y de cierta consideración entre los cordobeses de aquel tiempo y posiblemente pariente del que nos referirnos a continuación.

Hemos encontrado un documento en el que se relacionan todos los pleitos que Córdoba tiene pendientes en la Chancillería de Granada en el año 152733; entre ellos se halla uno por un asunto de mancebía, contra Alonso de Molina, que es el Contador Mayor de Córdoba, el cual, por ser un experto contable, es comisionado por el Regimiento municipal para negociar en la Corte el encabezamiento de las rentas de la ciudad ${ }^{34}$.

Por todo lo expuesto no podemos pasar por alto el lucro directo que el Ayuntamiento cordobés obtenía de los dueños de estas boticas a través de los gravámenes que habían de pagar sus propietarios o explotadores, pero tampoco podemos obtener el prorrateo de lo abonado por cada una de las casas y el mesón de las que nos habla Alonso de Molina, ya que en el referido documento no se menciona. Ciertamente no tenemos instrumentos para hallarlo, pero entendemos que, al haber tantas casas y mesones en los que se practicaba la putería, los cobros de los Cabildos cordobeses, lo mismo el

32 Padilla González, J y Escobar Camacho, J. M. Op. cit, pág. 284

33 A.H.M. CO. AH-16.04.01. Sección XVI. Asuntos judiciales. Pleitos civiles. Caja 1306.

34 Idem. Actas capitulares. Sesión del 27-9-1533. 
municipal que el catedralicio, por este concepto serían de elevada cantidad, lo que proporcionaría a ambos una saneada fuente de ingresos.

Finalizamos diciendo que directa o indirectamente todos los que regentan este tipo de negocio obtienen provecho económico de la deplorable situación en la que viven estas desafortunadas mujeres.

\section{ConClusión}

Según hemos visto en las fuentes documentales estudiadas, la regulación jurídica de la prostitución poseía una orientación económica que no esconde la redacción de los textos legales de la época. Esta dimensión patrimonial se traducía en una serie de controles reglamentados por el poder público, insertos en un entramado social y comercial en el que las prostitutas eran el elemento más débil. Este estado de marginación se hace especialmente patente al comprobar el alejamiento entre las abstractas previsiones jurídicas y su aplicación real lo que, amén de agravar la precariedad del colectivo de dichas mujeres, generaba unos desajustes en el sistema que obligaba a la constante actividad correctora de las autoridades mediante la cual también intentaban mantener la salud, el buen orden dentro de la sociedad, y que las meretrices no se confundiesen con aquellas que no practicaban tal profesión. 


\section{FuENTES Y SUCINTA BIBLIOGRAFÍA}

\section{FUENTES MANUSCRITAS}

Archivo Histórico Municipal de Córdoba.

Actas Capitulares. Signatura L-36

Ordenanzas municipales. L-1905.

Sección: Fuero, privilegios, Acontecimientos reales y Docum. Miscelánea. Subsección: Mancebía. Serie: Disposiciones y expedientes.

\section{Bibliografía}

Alfonso X El Sabio, Las Siete Partidas

Alma Mater Hispalense, Siglo XVI La prostitución en la Sevilla del Siglo XVI.

personal.us.es/alporu/histsevilla/prostitucion.htm. Fecha consulta 1211-2011.

-Reglamentación burdeles siglo XVI. Ordenanzas mancebía Sevilla ...

personal.us.es/alporu/histsevilla/burdeles_reglam.htm. Fecha consulta 12-11-2011.

Benito Juliá, R. Prostitución y Alcabuetería en la BCN del Siglo X, Miscelánea Medieval Murciana, XXXII (2008); pp. 9-21 ISSN 0210-4903. Enlace Web www.scribd.com > Research > History. Fecha de consulta 24-12-2011.

Carboneres, M. Picaronas y Alcahuetes o La Mancebia en Valencia. Apuntes para la Historia de la Prostitución. Valencia. Editorial Bonaire (En Disolución). 1978.

Cobos Ruiz de Adana, José. Delincuencia y sexualidad en la Córdoba Barroca. Cursos de Verano. El Barroco en Andalucía. Universidad de Córdoba. Excm ${ }^{a}$. Diputación Provincial. Tomo II. Córdoba, 1984.

García Herrero, $\mathrm{M}^{\mathrm{a}}$ del Carmen, Prostitución y amancebamiento en Zaragoza a fines de la Edad Media. En la España Medieval. No 12. 1989. 
Herreros Gonzáles, C. y Santapau Pastor, M. C. Prostitución y matrimonio en Roma: ¿Uniones de hecho o de derecho? Iberia, nº 8, 2005. pp. 89-111.

Hontañón de, Pascual y la prostitución gaditana del último tercio del siglo XIX; saber médico frente a moralidad pública: Trocadero: Revista de historia moderna y contemporánea, ISSN 0214-4212, No 2, 1990 , págs. $217-230$

Maravall, J.A. El mundo social de «La Celestina». Biblioteca virtual Miguel de Cervantes, 2003

Moreno Mengíbar, A. y Vázquez García, F. Poderes y Prostitución en España (siglos XIV-XV). El Caso de Sevilla. Criticón. Núm. 69, 1997. Págs 33-49. Centro Virtual Cervantes.

Padilla González, Jesús y Escobar Camacho, José Manuel, Actas del III Congreso de Historia Medieval Andaluza. Diputación Provincial de Jaén, 1984. La Sociedad Medieval Andaluza: Grupos no privilegiados. La Mancebía de Córdoba en la Baja Edad Media. Depósito Legal: J. 706-1984. I.S.B.N.: 84-5050834-7.

Paola Zapatero, M. Sobre mancebas y mancebias en los siglos XIV-XV. Enlace web: www.uca.edu.ar/uca/common/grupo17/files/Zapatero2-2.pdf-. Fecha consulta 12-11-2011

Vázquez García, F y Moreno Mengíbar, A. Poder y Prostitución en Sevilla. Universidad de Sevilla. Colección de Bolsillo. Universidad de Sevilla. Secretariado de Publicaciones. ISBN (Tomo I) 87-472-0238-0.

-El Ocaso de las mancebias castellanas. Historia 16, n 306, 2001, págs. 39-47 ISSN 0210-6353. 


\section{Pequeño APÉndice documental}

\section{Real Provisión de la Reina $D^{a}$ Juana, hecha en Plasencia el 7-12-1515 dirigida al caballero corregidor de Córdoba para que los alguaciles mayores ni sus tenientes lleven los dineros que llevan a los almojarifes, a los factores ni a los arrendadores de las penas del vino de fuera ni a las mujeres de la mancebía.}

$\mathrm{D}^{\mathrm{a}}$ Juana por la graçia de Dios reina de Castilla e [...] sepades que yo he sido informada que los alguaciles mayores que hasta ahora ha habido en esa dicha çibad e los que ahora son, han llevado e llevan de los mis almojarifes de la dicha çibad e de sus [...] cien florines de oro por real que son obligados a se os dar porque les dan las llaves de las puertas de la dicha çibad e así mismo dice que han llevado e llevan en cada [...] cuero de vino cinco cántaras e media de los arrendadores de las penas del vino de esa dicha çibad e un real de plata de cada mujer [...] mancebía a quien dan licencia para que salga a dormir fuera de la casa de la mancebía e porque los dichos dineros son mal e injustamente llevados, los del mi Consejo [...] que debía mandar dar esta mi carta de mandato expresamente de [...] del dicho alguacil mayor [...] de la dicha çibad por vos el dicho don Antonio de la Cueva e todos e otros alguaciles mayores [...] por tiempo fueren en esa dicha çibad e a cada uno de ellos que de aquí adelante ellos ni alguno de ellos sean osados [...] de pedir ni llevar por vía [...] dichos florines a los dichos almotacenes ni el dicho vino de los dichos arrendadores de las dichas penas ni los dichos reales de las dichas mujeres de la manera [...] fasta aquí diz que lo han pedido e llevado no [...] ganar [...] e costumbre en que [...] que todo lo que llevaren lo paguen con la [...] para la mi cámara e [...] e mando a vos los dichos mis corregidores e jueces de la dicha çibad que no consintáis ni deis lugar que los dichos alguaciles mayores [...] de ellos ni lleven las costas [...] e cumpláis esta mi carta según e como en ella se contiene e [...] ejecutéis e fagades ejecutar las penas en ella contenidas con los dichos alguaciles que en ellas vinieren e incurrieren e porque [...] dicha sea público e notorio a ninguno de ellos [...] mando que esta mi carta sea pregonada públicamente en esa dicha çibad en las plazas e mercados de esa por pregonero e ante escribano público e que después de pregonada sea puesta [...] del Concejo merced e de diez mil maravedíes para la mi cámara. Dada en la çibad de Plasencia a siete días del mes de diciembre año del nascimiento de nuestro salvador Jesucristo de mil e quinientos e quince años. 
Fondo: ARCHIVO MUNICIPAL HISTÓRICO DE CÓRDOBA

Sección: FUERO PRIVILEGIOS ACONTECIMIENTOS REALES Y DOCUM. MISCELANEA

Subsección: Mancebía

Serie: Disposiciones normativas y expedientes. Signatura: C 0016004

Ident. Regist: 10.586 


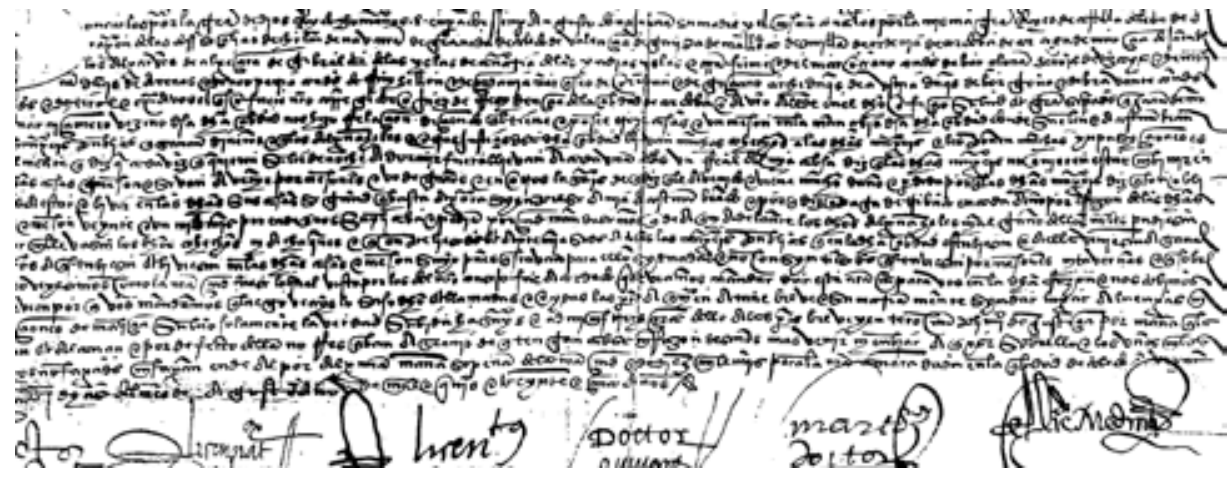

\section{TRANSCRIPCIÓN}

Real Provisión de Su Majestad y Señores del Concejo hecha en Toledo a 25 de Agosto de 1525 por la cual le manda al Caballero Corregidor de Córdoba administre justicia en la queja que se había dado por el dueño de la Mancebía sobre las vejaciones que los alguaciles hacían a las mujeres de ella.

D. Carlos por la graçia de Dios, Rey de Romanos y Emperador semper augusto, $\mathrm{D}^{\mathrm{a}}$ Juana, su madre y el mismo D. Carlos por la misma gracia reyes de Castilla...etc. a vos el que es o fuere nuestro Corregidor o Juez de Residencia de la çibdad de Córdoba o a vuestro Alcalde en el dicho ofiçio salud et graçia, sepades que Juan Molina, guarniçionero, vecino de la dicha çibdad me hizo relación diçiendo que él tiene y posee trece casas y un mesón en la mancebía de esa dicha çibdad donde suelen e acostumbran estar mujeres públicas que ganan dineros e que los alguaciles e otras justicias de esa dicha çibdad llevan muchos cohechos a las dichas mujeres e les ponen muchas imposiciones especialmente que diz que cada vez que quieren salir de noche a dormir fuera llevan a cada una de ellas un real, a cuya cabsa diz que las dichas mujeres no quieren estar en las dichas casas e mesones e se van a vivir por mesones e bodegones e en otros lugares de que diz que le ha venido e viene mucho daño e pérdida porque las dichas mujeres diz que se ven obligadas a estar e vivir en las dichas sus casas según que hasta agora siempre se habían acostumbrado e porque diz que paga de tributo en cada año por razón de las tres casas e un mesón veinte e un mil maravedíes, por ende que nos suplicaba e pedía por merced que de aquí adelante los dichos alguaciles ni alguno de ellos no les puedan llevar ni llevasen los dichos cohechos ni achaques y que compeliesedes e apremiasedes a las dichas mujeres públicas que en la dicha çibdad estuviesen o a ella viniesen [...] dineros e que estuviesen 
e viviesen en las dichas casas e mesón suyos pues que estaban para ello habituadas y no consintiésedes que estuviesen por mesones ni tabernas e en ello proveyésemos como la nuestra merced fuese lo cual visto por los del nuestro Consejo fue acordado que debíamos mandar esta nuestra carta para vos en la dicha razón e nos hubímosla por bien porque vos mandamos que luego veáis lo suso dicho e llamadas e oídas las partes a quien atañe breve e sumariamente sin dar lugar al [...] dilaciones de malicia salvo solamente la verdad sabida hayáis e administréis çerca de ello a las partes breve y entero cumplimiento de justicia por [...] ayan e alcançan e por defecto de ella no reciban agravio de que tengan cabsa ni razón de nos más venir ni enviar a que falle sobre ello e los unos e los otros no fagades ni fagan ende al por alguna manera so pena de la nuestra merced e de diez mil maravedíes para la nuestra Cámara. Dada en la çibdad de Toledo a veinticinco días del mes de agosto del año de mil e quinientos e veinte e çinco años.

Fondo: ARCHIVO MUNICIPAL HISTÓRICO DE CÓRDOBA

Sección: FUERO PRIVILEGIOS ACONTECIMIENTOS REALES Y DOCUM. MISCELANEA

Subsección: Mancebía

Serie: Disposiciones normativas y expedientes. Signatura: C 0016005. Ident. Regist.: 10. Ident. Regist: 10.586 
Copia del documento original del Concejo y Corregidor de Córdoba, sobre atuendo prostitutas y otras cosas

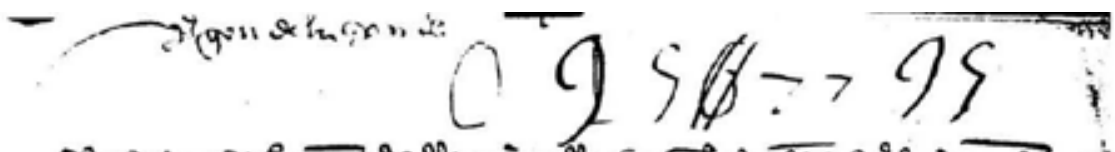

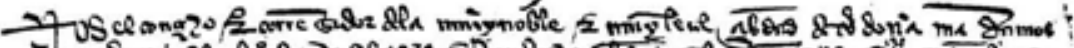

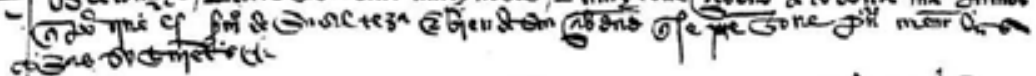

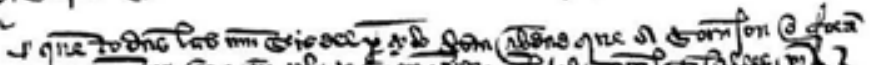

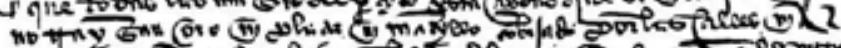

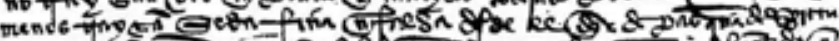

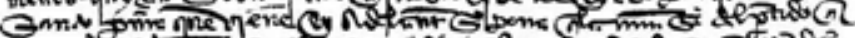

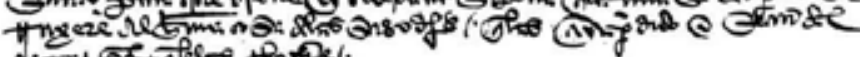 तesnare ofine tiomer.

Gytem ans

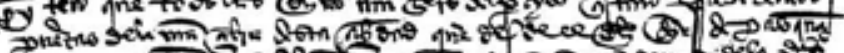

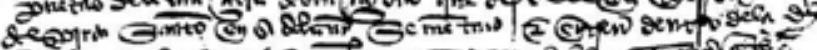

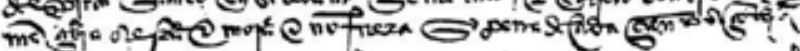

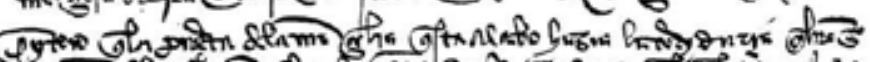

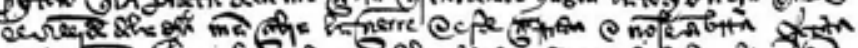

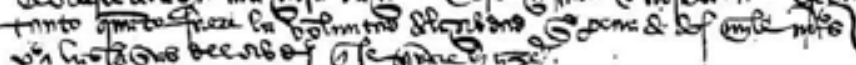

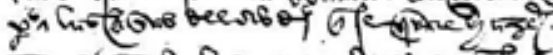

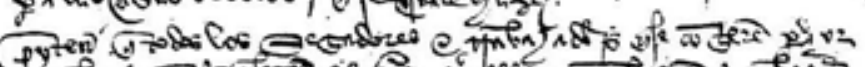

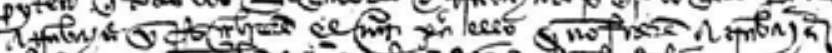

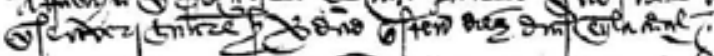

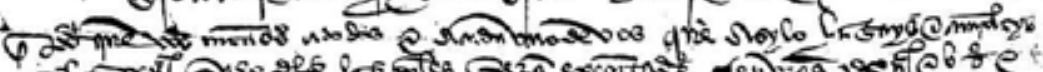

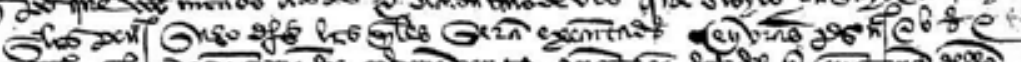

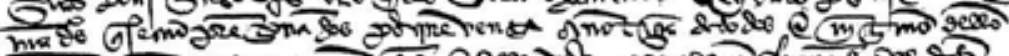

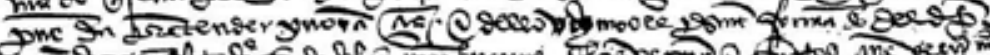
हn \&.
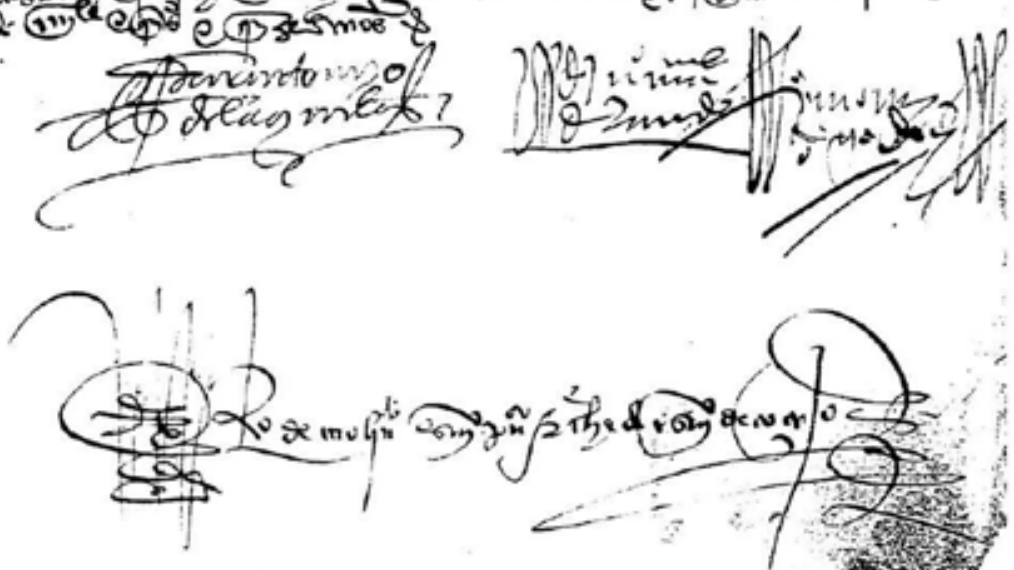

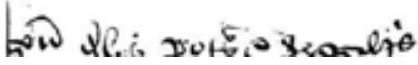




\section{TransCripción}

Nos el Concejo e Corregidor de la muy noble e muy leal çibdad de Córdoba mandamos que porque es servido de su alteza e bien de esta çibdad que se pregone primeramente las cosas siguientes:

Que todas las mujeres el partido de esta çibdad que agora son o fueren no traigan oro ni plata ni mantillo cobijado por calles ni menos traigan seda fina desde el día de pascua del Espíritu Santo primero que viene en adelante, so pena que la mujer del partido que trajere alguna cosa de las suso dichas que las hayan pedido e que no de algunas que se las tuviere.

Item que todas las dichas mujeres del partido que están fuera de las dos puertas de la mancebía de esta çibdad que desde el dicho día de pascua del Espíritu Santo en adelante se metan e entren dentro de la dicha mancebía a estar e morar e no fuera, so pena de cada una cien azotes.

Item que la puerta e la mancebía que está al lado hacia la curtiduría que luego de allí de la dicha mancebía la cierren e esté cerrada e no se abra fasta tanto cuanto fuere la voluntad de la çibdad so pena de dos mil maravedíes para las casas del abasto que se quiere hacer.

Item que todos los segadores e trabajadores que se cogieren para ir a trabajar y recibieren el maravedí para ello y no fuesen a trabajar y se averiguare ser verdad que estén diez días en la cárcel.

Por lo que vos mandamos a todos e cada uno de vos que así lo hagáis e cumpláis so las penas de suso dichas, las cuales serán ejecutadas en vuestras personas e bienes e mando que sean pregonados porque venga a noticia de todos e ninguno de ello pueda pretender ignorancia e de ello nos le presentamos firmado del dicho señor corregidor e de los dichos omes buenos de los veinticuatro que vean como hazienda de Rodrigo de Mexía, escribano de Concejo que es fecho en la dicha çibdad de Córdoba a XVIII días del mes de mayo de mil e quinientos e quince años.

Rodrigo de Molina escribano público e [...] escribano del Conçejo. 
Fondo: ARCHIVO MUNICIPAL HISTÓRICO DE CÓRDOBA

Sección: FUERO PRIVILEGIOS, ACONTECIMIENTOS REALES Y DOCUM. MISCELÁNEA

Subsección: Mancebía

Serie: Disposiciones normativas y expedientes

Cod. Archivo: 01.17.01 Signatura 0016003 Ident. Regist: 10.585. 